\title{
Neutrophil gelatinase-associated lipocalin to predict cardiac surgery-associated acute kidney injury: A holy grail or just another fancy cup?
}

\author{
Rakesh C. Arora, MD, PhD, FRCSC, ${ }^{\mathrm{a}, \mathrm{e}}$ Claudio Rigatto, MD, MSc, FRCPC, ${ }^{\mathrm{b}, \mathrm{d}}$ and \\ Rohit K. Singal, MD, MSc, FRCPC ${ }^{\mathrm{a}, \mathrm{e}}$
}

\footnotetext{
From the Departments of ${ }^{\text {a Surgery, }}{ }^{\mathrm{b}}$ Medicine, and ${ }^{\mathrm{c}}$ Community Health Sciences, University of Manitoba; ${ }^{\mathrm{d} C h r o n i c ~ D i s e a s e}$ Innovation Centre, Seven Oaks Hospital; and ${ }^{\mathrm{e}}$ Cardiac Sciences Program, St. Boniface Hospital, Winnipeg, Manitoba, Canada.

Disclosures: R.C.A. is the recipient of an unrestricted educational grant from Pfizer Canada Inc. All other authors have nothing to disclose with regard to commercial support.

Received for publication Feb 12, 2016; accepted for publication Feb 19, 2016; available ahead of print March 22, 2016.

Address for reprints: Rakesh C. Arora, MD, PhD, FRCSC, St Boniface Hospital, CR3012, 369 Tache Ave, Winnipeg, MB, Canada R2H 2A6 (E-mail: rakeshcarora@gmail.com).

J Thorac Cardiovasc Surg 2016;151:1482-3

$0022-5223 / \$ 36.00$

Copyright (c) 2016 by The American Association for Thoracic Surgery

http://dx.doi.org/10.1016/j.jtcvs.2016.02.042
}

Cardiac surgery-associated acute kidney injury (CSA-AKI) continues to be an important clinical outcome following cardiac surgery. Severe renal injury (ie, requiring new dialysis) occurs in approximately $2 \%$ of patients after cardiac surgery with cardiopulmonary bypass (CPB). ${ }^{1,2}$ Significant renal injury is associated with a $60 \%$ mortality risk and high rates of rehospitalization. ${ }^{2,3}$ Importantly, previous seminal investigations have demonstrated that even milder forms of perioperative renal injury (defined as a $25 \%$ delta change in serum creatinine from baseline) following cardiac surgery are associated with substantial short- and long-term mortality. 4,5

CSA-AKI most likely results from baseline patient renal vulnerability and new intraoperative insult, with the prevailing mechanism thought to be secondary to ischemiareperfusion (IR). Experimental data suggest that AKI secondary to IR may be reversible if identified early to permit therapeutic intervention to mitigate further harm. ${ }^{6,7}$

As deGeus and colleagues ${ }^{8}$ highlight in this issue of the Journal, the diagnosis of new acute renal injury is currently based on urine output and serum creatinine thresholds using the RIFLE (risk, injury, failure, loss, and end-stage kidney disease) criteria, 9,10 the Acute Kidney Injury Network criteria, ${ }^{11}$ or the Kidney Disease: Improving Global Outcomes AKI Working Group definition. ${ }^{12}$ For each of these definitions, the diagnosis of new renal injury can take 2 to 3 days, a delay imposed by the rate of rise of creatinine in response to an abrupt loss of glomerular filtration rate. Importantly, interventions administered at the time of current AKI diagnosis using elevated serum creatinine level may not be effective, as has been demonstrated in multiple clinical trials of promising therapies for AKI in humans. As such, research over the last decade has focused on identification of novel biomarkers detectable during the reversible phase of renal and therapy.

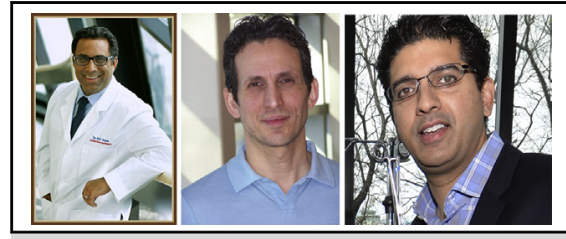

Rakesh C. Arora, MD, PhD, FRCSC, Claudio Rigatto, MD, MSC, FRCPC, and Rohit K. Singal, MD, MSC, FRCPC

\section{Central Message}

Subclinical acute kidney injury (AKI), defined as an elevation in renal tubular injury markers in the absence of clinically overt AKI, is a bold concept demanding further study.

See Editorial page 1476.

injury, thereby paving the way for more timely diagnosis

de Geus and colleagues ${ }^{8}$ have suggested a bold twist to the paradigm: suppose that the biomarker of tubular injury can predict these outcomes better than the creatinine-based AKI surrogate? What if the tubular injury, and not the intermediate functional consequence, was the more important event? As is appropriate for a conceptual work, the authors elaborate a detailed hypothesis drawn from, but not yet proven by, current scientific evidence. The 3 key components of their proposed framework are that subclinical AKI, manifested by markers of tubular injury, such as neutrophil gelatinase-associated lipocalin (NGAL), (1) is not always expressed as clinical AKI defined by standard creatinine based criteria, (2) is nevertheless a strong predictor of important patient outcomes, and (3) when detected early, will be amenable to immediate interventions that ultimately will improve these downstream clinical outcomes. Although point 1 is strongly supported by clinical evidence, points 2 and 3 require further proof. In particular, evidence is needed that subclinical AKI (as defined by NGAL) significantly improves the prognostic information clearly afforded by creatinine-based AKI classifications. Finally, there is no proof that interventions triggered by detection of subclinical AKI, will meaningfully improve patient outcomes. This evidence should be sought before proceeding with clinical implementation. Without this 
evidence, implementing the recommendations suggested by de Geus and colleagues ${ }^{8}$ could have the impact of significantly altering patient flow without any proven benefit. Furthermore, the additional cost related to diagnostic tests and appropriate human resources for processing and interpretation are not warranted if no demonstration of clinical benefit is found.

As with all hypotheses, theoretical appeal is no guarantee of ultimate truth. There are many possibilities for failure and proof of concept by way of scientific inquiry is mandatory. To date, the examination of this topic, which has been significant, has not provided a clear signal that detection of subclinical AKI using NGAL will pan out as the authors hope. In fact, a recent meta-analysis of biomarkers in the early detection of AKI following cardiac surgery has provided insights to potential limitations of NGAL and other urine and serum biomarkers. ${ }^{13}$ That review found that all of the currently studied biomarkers generally had at best moderate discrimination for AKI when measured within the first 24 hours after cardiac surgery in adults. Furthermore, even though NGAL is the only biomarker that has been studied more than once, its intraoperative diagnostic performance is somewhat limited. This may be why a randomized controlled trial using only NGAL to guide therapeutics has not yet been performed.

In conclusion, the concept of subclinical AKI is novel and valuable, and we agree wholeheartedly that it should inform future research. de Geus and colleagues ${ }^{8}$ state that the NGAL score should be implemented now because there is "little foreseeable downside." We congratulate the authors on their call to action, and encourage them to broaden the concept with consideration of additional biomarkers of subclinical AKI. Nonetheless, it must be clearly understood that the proposed scheme is hypothetical and is solely a research tool at this time. Robust evidence of clinical benefit is needed before this scheme can be broadly implemented in clinical practice.

\section{References}

1. Ho J, Reslerova M, Gali B, Nickerson PW, Rush DN, Sood MM, et al. Serum creatinine measurement immediately after cardiac surgery and prediction of acute kidney injury. Am J Kidney Dis. 2012;59:196-201.

2. Thakar CV, Arrigain S, Worley S, Yared J-P, Paganini EP. A clinical score to predict acute renal failure after cardiac surgery. J Am Soc Nephrol. 2005;16:162-8.

3. Brown JR, Parikh CR, Ross CS, Kramer RS, Magnus PC, Chaisson K, et al. Impact of perioperative acute kidney injury as a severity index for thirty-day readmission after cardiac surgery. Ann Thorac Surg. 2014;97:111-7.

4. Mangano CM, Diamondstone LS, Ramsay JG, Aggarwal A, Herskowitz A, Mangano DT. Renal dysfunction after myocardial revascularization: risk factors, adverse outcomes, and hospital resource utilization. The Multicenter Study of Perioperative Ischemia Research Group. Ann Intern Med. 1998;128:194-203.

5. Loef BG, Epema AH, Smilde TD, Henning RH, Ebels T, Navis G, et al. Immediate postoperative renal function deterioration in cardiac surgical patients predicts in-hospital mortality and long-term survival. J Am Soc Nephrol. 2005; 16:195-200.

6. Devarajan P. Update on mechanisms of ischemic acute kidney injury alterations in morphology. J Am Soc Nephrol. 2006;17:1503-20.

7. Mishra J, Mori K, Ma Q, Kelly C, Yang J, Mitsnefes M, et al. Amelioration of ischemic acute renal injury by neutrophil gelatinase-associated lipocalin. J Am Soc Nephrol. 2004;15:3073-82.

8. de Geus HRH, Ronco C, Haase M, Jacob L, Lewington A, Vincent JL. The cardiac surgery-associated neutrophil gelatinase-associated lipocalin (CSA-NGAL) score: A potential tool to monitor acute tubular damage. J Thorac Cardiovasc Surg. 2016;151:1476-81.

9. Bellomo R, Kellum J, Ronco C. Defining and classifying acute renal failure: from advocacy to consensus and validation of the RIFLE criteria. Intensive Care Med. 2007;33:409-13

10. Bellomo R, Ronco C, Kellum J, Mehta RL, Palevsky P. Acute renal failure: definition, outcome measures, animal models, fluid therapy and information technology needs. The Second International Consensus Conference of the Acute Dialysis Quality Initiative (ADQI) group. Crit Care. 2004;8:R204-12.

11. Mehta RL, Kellum J, Shah SV, Molitoris BA, Ronco C, Warnock DG, et al. Acute Kidney Injury Network: report of an initiative to improve outcomes in acute kidney injury. Crit Care. 2007;11:R31.

12. Kidney Disease: Improving Global Outcomes (KDIGO) CKD Working Group. KDIGO clinical practice guideline for the evaluation and management of chronic kidney disease. Kidney Int Suppl. 2012;2:1-138.

13. Ho J, Tangri N, Komenda P, Kaushal A, Sood M, Brar R, et al. Urinary, plasma, and serum biomarkers' utility for predicting acute kidney injury associated with cardiac surgery in adults: a meta-analysis. Am J Kidney Dis. 2015;66:993-1005. 